\title{
Pattern and correlates of tobacco smoking among mentally ill male patients in El-Mamoura Psychiatric Hospital, Alexandria, Egypt
}

\author{
Original Mervat W. Abu Nazel', Heba M. Elkady', Sherif Abd Allah', Riham Ibrahim ${ }^{3}$ \\ Article \\ ${ }^{1}$ Mental Health, ${ }^{2}$ Geriatric Health, Department of Family Health, High Institute of \\ Public Health, Alexandria University, Egypt, ${ }^{3}$ El-Mamoura Hospital for Psychiatry \\ and Addiction, Ministry of Health, Alexandria, Egypt
}

\begin{abstract}
Background: Despite widespread concern in public health regarding the increasing prevalence and burden of smoking and mental disorders, little is known about the double burden of these problems in Arab countries.

Aim: To describe pattern and identify determinants of smoking among mentally ill male patients in El-Mamoura Psychiatric Hospital, Alexandria, Egypt.

Materials and Methods: A cross-sectional study was conducted on 300 randomly selected adult male outpatients receiving formal diagnosis of one or more mental disorders according to Diagnostic and Statistical Manual of Mental DisordersIV criteria by a senior psychiatrist. A predesigned structured interviewing questionnaire and an Arabic translation of Fagerstrom test for nicotine dependence were used to collect data.

Results: The study indicated that $68.7 \%$ of patients were current daily smokers and $58.2 \%$ of them were high nicotine dependent. Smoking was significantly associated with single and dual diagnoses of schizophrenia spectrum disorder and bipolar disorder (odds ratio $=2,3.1,3.9$, respectively).

Conclusion: Professionals working with people with mental disorders should be trained in raising awareness of smoking health outcomes and provision of counseling quit services.
\end{abstract}

Received: 25 July 2017, Accepted: 08 Sep 2017

Key Words: Egypt, Fagerstrom Test for Nicotine Dependence, mental illness, pattern of tobacco smoking, shisha smoking, smoking quit motivators and barriers.

Corresponding Author: Heba M. Elkady, Ph.D., Department of Family Health, High Institute of Public Health, Alexandria University, Alexandria, Egypt, Tel.: 01001235843, E-mail: heba_elkady2004@yahoo.com

ISSN: 0013-2446, Vol. 92, No.3

\section{INTRODUCTION}

Owing to their increasing prevalence and the associated considerable burden, smoking and mental disorders have received widespread concern from public health professionals $^{[1]}$. Several studies indicated high prevalence of smoking among mentally ill persons ${ }^{[2,3]}$. Centers for Disease Control and Prevention, 2013, reported that a person with a mental illness is $70 \%$ more likely to smoke than a person without a mental illness ${ }^{[4]}$. Smoking rates among adults with depression are twice as high as among adults without depression ${ }^{[2]}$. Moreover, smoking rates among people with schizophrenia and bipolar disorder are significantly higher than those in the general population, with prevalence estimated to be as high as 88 and $82.5 \%$, respectively ${ }^{[5,6]}$.

Although prevalence of smoking has not been well evaluated in many developing countries ${ }^{[7]}$, far less few studies have addressed smoking patterns among mentally ill in the Arab region. A study conducted among primary healthcare mentally ill attendees at Al-Qassim region in Saudi Arabia revealed that $52.3 \%$ of them were current smokers $^{[8]}$. In an earlier Egyptian study (2007), it was found that smoking rate among patients with schizophrenia ranged between 85.3 and $90.6 \%{ }^{[9]}$.

Despite evidence for an existing association between smoking and mental illness, the direction of such relationship is greatly doubted. It is not clear whether smoking is the cause or effect of mental illness; although some researchers believe that smoking could act as a trigger for mental illness ${ }^{[6,10]}$, others suggest that smoking may play a role in the onset of mental illness ${ }^{[7,11]}$.

There are a number of mechanisms that could explain such association. Although people with mental illness use tobacco for the same reasons as the general population, there are additional factors that contribute to the higher prevalence of smoking among mentally ill patients ${ }^{[10]}$. One possible explanation is that people with schizophrenia use smoking to manage some of the symptoms associated with their illness and that tobacco lessens some of the adverse effects of their medication ${ }^{[6]}$. Research has also shown that smoking may improve attention and short-term memory and stimulate the subcortical reward system and the prefrontal cortex, both of which malfunction in people with schizophrenia ${ }^{[12]}$. The relationship between smoking 
and depression was attributed to genetic predisposition, low level of dopamine, low self-esteem, and coping styles $^{[6]}$.

Research evidence indicates that smokers with serious mental illness have higher hospitalization rates, higher medication doses, and more severe psychiatric symptoms compared with their nonsmoking counterparts. Furthermore, smoking results in substantial health, social, and financial costs to the patients, their families, and the society ${ }^{[13]}$

\section{AIM OF THE STUDY}

Considering the double burden of smoking and mental disorders, and the scarcity of studies examining this issue in Egypt, the present work aimed at studying smoking and quitting behaviors of mentally ill patients attending the outpatient clinic of El-Mamoura Psychiatric Hospital in Alexandria.

\section{MATERIALS AND METHODS}

A cross-sectional study was conducted in the outpatient clinic of El-Mamoura Psychiatric Hospital in Alexandria, Egypt, during the period 2014-2015. The sample size was calculated using the computer package EPI-INFO version (2002) software, (CDC, Atlanta, GA), based on a $75 \%$ prevalence of smoking among patients with mental illness ${ }^{[14]}$, with a precision of $5 \%$ and confidence level of $95 \%$; the minimum required sample amounted to 289 , which was rounded to 300 .

The study included patients aged from 18 to 60 years and diagnosed with one or more mental disorders by a senior psychiatrist. Patients with neurological or communication problems, abusers of substances other than nicotine, and current inpatients were excluded. A systematic random sampling method was used; every fifth male patient attending the aforementioned clinic and fulfilling the eligibility criteria was included. The clinic was visited 3 days per week till the predetermined sample was completed.

\section{Data collection}

During the first stage of the study, male patients attending the aforementioned study setting were subjected to psychiatric clinical interview by one of the researchers to recruit study participants and to confirm their formal diagnoses according to Diagnostic and Statistical Manual of Mental Disorders-IV criteria. In addition, participants' files were reviewed to collect data concerning previous diagnoses, treatments received, and history of hospitalization. Sampled study participants were further subjected to a predesigned structured interviewing questionnaire to collect history of current mental illness and sociodemographic data including age, marital status, education, occupation, and income per month.

\section{Smoking status and pattern}

Smoking status of participants was assessed using four 'yes' or 'no' questions, and they were classified into never smokers (those without history of smoking or smoking trial for once or twice), ex-smokers (those who used to smoke but stopped $\geq 2$ weeks ago), and current smokers (those who smoked daily for the past 30 days). Current smokers were further subjected to 20-item questionnaire to assess age of smoking initiation, intensity of cigarette smoking, shisha smoking, previous quit trials, motivators, and barriers to quitting.

\section{Level of nicotine dependence}

Fagerstrom test for nicotine dependence (FTND) ${ }^{[15]}$ is the most widely used tool for the assessment of nicotine dependence. It is a screening instrument that consists of six items used to help the physicians to determine the suitable treatment regimen for cessation. It relates to a number of variables associated with dependency such as plasma levels of nicotine and withdrawal symptoms. Patients with high scores on the FTND have the greatest difficulty refraining from smoking and receive the greatest therapeutic benefits from nicotine substitution ${ }^{[16]}$.

FTND was subjected to forward and backward translation, and the adapted reliability of the Arabic version was very good with Cronbach's $\alpha=0.857$. Factor analysis revealed that there were two extracted factors. The first factor included four items: smoking even when very ill, number of cigarettes per day, frequency of smoking during the first hours of awaking and time of the first cigarette after waking up. The second factor included two items: the most important cigarette of the day and finding difficulty to refrain from smoking at areas where smoking is forbidden. The factor solution explained $50.7 \%$ of the total variance (moderate effect).

Patient's responses on the FTND were scored as follows: the three yes/no items were scored 0 for no responses and 1 for yes, two multiple choice items scored from 0 to 3 , and one multiple choice item scored 0 or 1 . Scores of items were summed to yield a total score of $0-10$. The scores obtained on the test permit the classification of nicotine dependence into five levels: very low ( $0-2$ points), low (3-4 points), moderate ( 5 points), high (6-7 points), and very high (8-10 points).

\section{Ethical considerations}

Approvals of the Ethics Committee of the High Institute of Public Health, on the basis of the Declaration of Helsinki, and the General Secretariat of Mental Health, were obtained before carrying out the study. Informed written consents were taken from the participants after ensuring confidentiality of data collected.

\section{Statistical analysis}

Data management and computations of descriptive statistics and prevalence were performed using SPSS, 
version 20 (SPSS Inc., Chicago, Illinois, USA). Differences with $\mathrm{P}$ value less than 0.05 were considered statistically significant. The mean with SD and percentage was used to describe the scale and categorical data, respectively, whereas median and range were used for skewed data with outliers. One sample KolmogorovSmirnov test was used for testing of distributional assumption for numerical data. The Pearson $\chi^{2}$ was used to test for the association between the categories of two independent samples, and Monte Carlo and Fisher exact tests were used if there were many small expected values. Odds ratio (OR) was also used to measure degree of association between independent and outcome variables.

\section{RESULTS}

Age of the sampled mentally ill male participants ranged from 18 to 60 years, with a mean of $37.9 \pm 9.5$ years. The highest percentage of the sample was urban residents $(91.7 \%)$, unemployed $(42.7 \%)$, illiterate or just read and write (36.7\%) and single (54.7\%), whereas $39.3 \%$ were married and $6.0 \%$ were divorced or widowed. More than two-thirds of the patients had sufficient monthly income $(69.7 \%)$, whereas the remaining $(30.3 \%)$ reported insufficient monthly income.

As illustrated in Fig. 1, most participants were current smokers (68.7\%), whereas ex-smokers and never smokers rated 18.7 and $12.6 \%$, respectively.

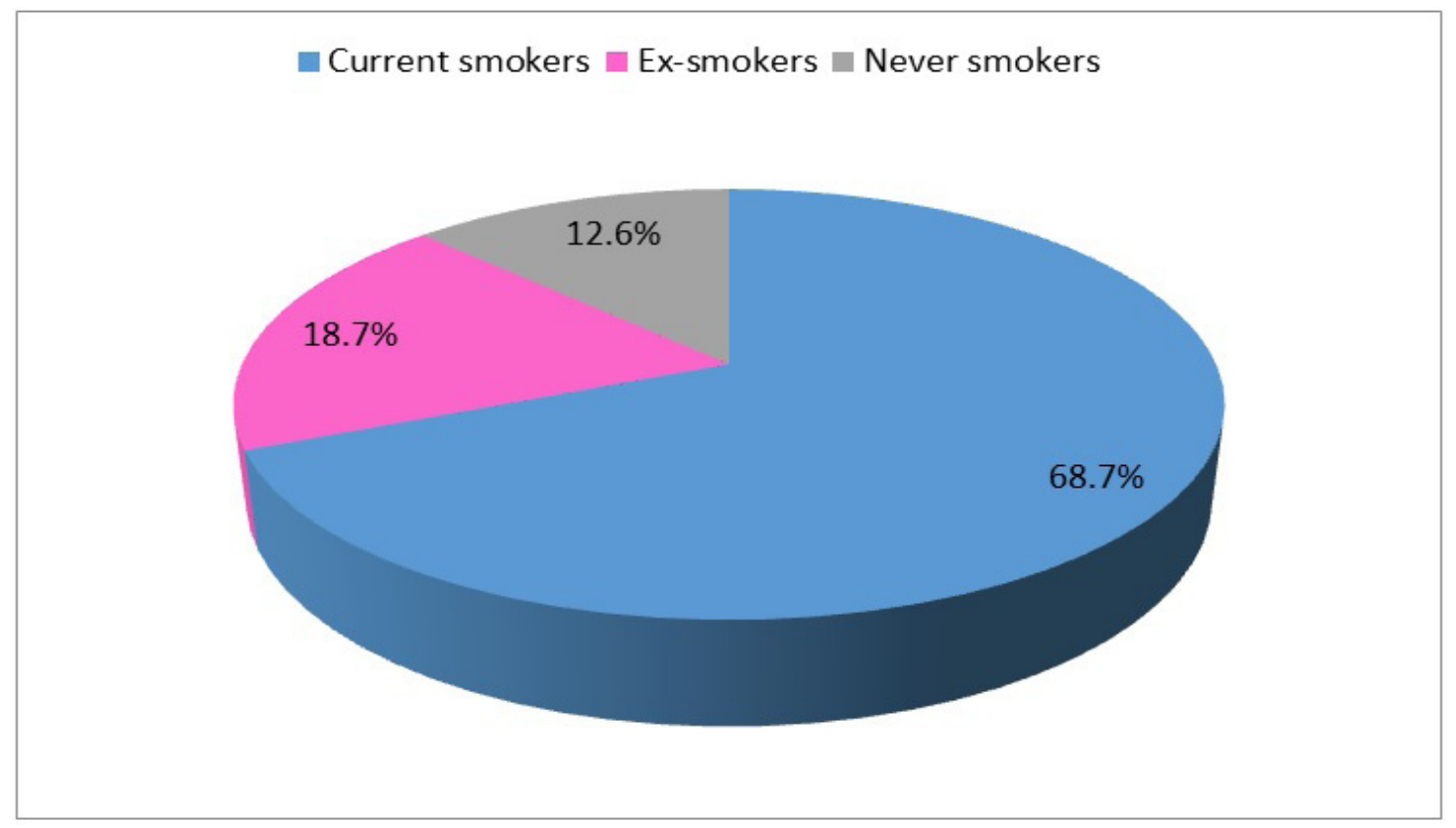

Fig. 1: Distribution of the sampled mentally ill patients according to their smoking status.

Table 1 indicates that the mean age of smoking initiation among sampled current smokers was $16.3 \pm 4.3$ years where most of them initiated smoking between 10 and less than 18 years of age (62.1\%). The highest percentage of them smoked between 10 and less than 20 cigarettes/day (52.9\%), whereas $28.1 \%$ smoked greater than 30 cigarettes/ day, and the remaining (14.6\%) smoked 20-30 cigarettes/ day. Patients who never smoked shisha represented $38.8 \%$ of the current cigarette smokers, whereas ex-shisha smokers and current shisha smokers rated 36.0 and $25.2 \%$, respectively. High/very high nicotine dependence was encountered among $58.2 \%$ of sampled current smokers, whereas moderate and low/very low nicotine-dependent participants rated 17.5 and $24.3 \%$, respectively. Nearly three-quarters of the sample tried to quit smoking $(75.7 \%)$, whereas only $24.3 \%$ did not have any previous trials. The duration of previous quit trials ranged from less than 1 to 72 months, and a median of 1 month; the reported quit durations were mostly few hours $(34.2 \%)$ or few days $(52.3 \%)$. The table also shows that the most frequently reported motivators of current smoking were habit (40.8\%), sense of loneliness $(31.1 \%)$, overcoming anxiety (28.6\%), and life stresses $(28.2 \%)$. Family and friends' pressure, overcoming negative feelings (sense of boredom, anger and frustration), and oppositional behavior rated 12.7, 6.8, and $4.9 \%$, respectively. The least reported motivator was weight control $(0.5 \%)$. Motivators for an upcoming quit trial were, namely, availability of cheap smoking cessation drugs (42.2\%), smoking cessation services (35.9\%), physician advice $(6.8 \%)$, raising cigarette price $(5.3 \%)$, and enforcement of smoke-free laws (4.4\%). It is worth noting that $44.2 \%$ of current smokers admitted that 'nothing' could motivate them to quit smoking. Professional quit advice was given by physicians $(61.5 \%)$ and psychiatrists $(41.3 \%)$ but no cessation counseling or treatment services were provided. 
Table 1: Distribution of the sampled mentally ill current smokers according to their smoking pattern, Alexandria, Egypt,2014-2015

\begin{tabular}{|c|c|}
\hline Pattern of smoking $(\mathrm{n}=206)$ & $\mathrm{n}(\%)$ \\
\hline \multicolumn{2}{|l|}{ Age of smoking initiation } \\
\hline$<10$ & $5(2.4)$ \\
\hline $10-<18$ & $128(62.1)$ \\
\hline $18-<30$ & $71(34.5)$ \\
\hline $30-40$ & $2(1.0)$ \\
\hline Mean \pm SD & $16.3 \pm 4.3$ \\
\hline \multicolumn{2}{|l|}{ Number of cigarettes/day (packs) } \\
\hline$<0.5$ & $9(4.4)$ \\
\hline 0.5 to $<1$ & $109(52.9)$ \\
\hline 1 to 1.5 & $30(14.6)$ \\
\hline$>1.5$ & $58(28.1)$ \\
\hline \multicolumn{2}{|l|}{ Status of shisha smoking } \\
\hline Never & $80(38.8)$ \\
\hline Ex-smokers & $74(36.0)$ \\
\hline Current & $52(25.2)$ \\
\hline \multicolumn{2}{|l|}{ Level of nicotine dependence } \\
\hline Low/very low & $50(24.3)$ \\
\hline Moderate & $36(17.5)$ \\
\hline High/very high & $120(58.2)$ \\
\hline \multicolumn{2}{|l|}{ Motivators to smoking } \\
\hline Habit & $84(40.8)$ \\
\hline Sense of loneliness & $64(31.1)$ \\
\hline Overcoming anxiety & $59(28.6)$ \\
\hline Life stresses & $58(28.2)$ \\
\hline Family and friends' pressure & $26(12.7)$ \\
\hline Overcoming negative feelings & $14(6.8)$ \\
\hline Oppositional behavior rated & $10(4.9)$ \\
\hline Weight control & $1(0.5)$ \\
\hline \multicolumn{2}{|l|}{ Number of quitting trials } \\
\hline None & $50(24.3)$ \\
\hline $1-2$ & $104(50.5)$ \\
\hline $3-5$ & $44(21.3)$ \\
\hline+6 & $8(3.9)$ \\
\hline \multicolumn{2}{|c|}{ Longest duration of quitting trials $(n=156)$} \\
\hline$<1$ day & $53(34.2)$ \\
\hline Days & $82(52.3)$ \\
\hline Weeks & $14(9.0)$ \\
\hline Months & $7(4.5)$ \\
\hline Median (months) & $1(<1-72)$ \\
\hline
\end{tabular}




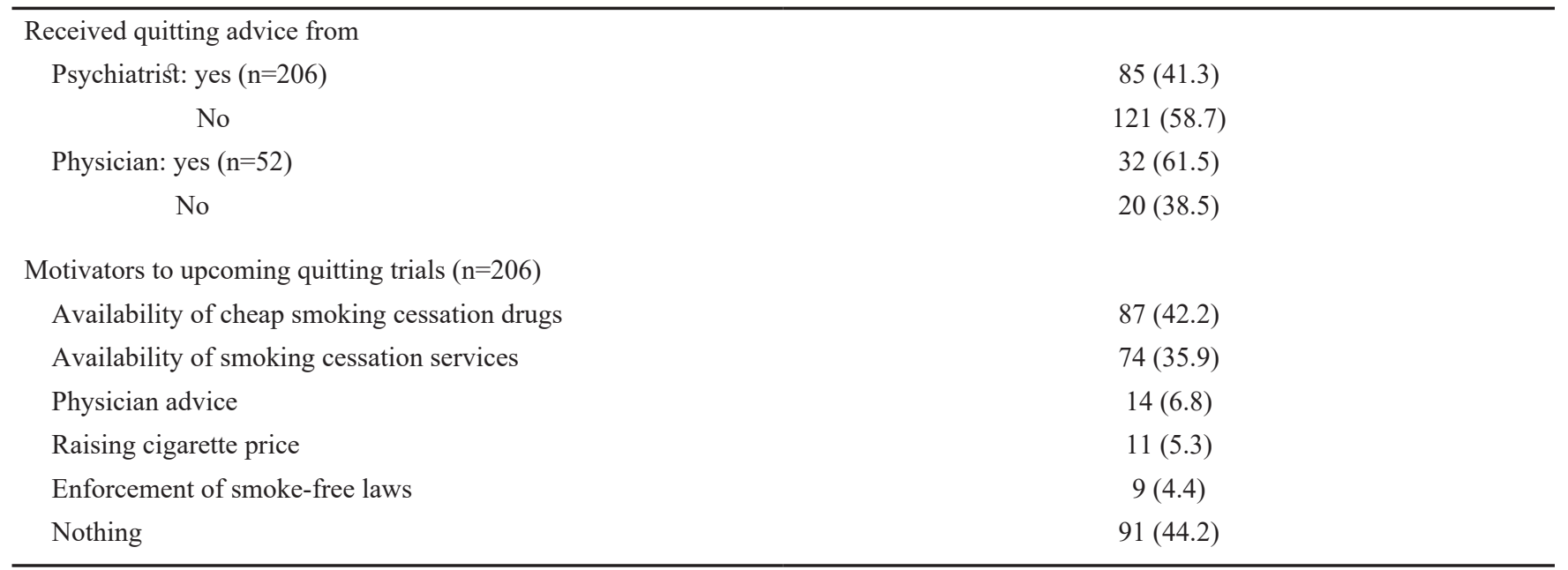

Table 2 shows that although the risk of being current smoker appeared to be higher among the oldest age group (50-60 years) $[\mathrm{OR}=1.7$, confidence interval $(\mathrm{CI})=0.72$ 3.8], married patients $(\mathrm{OR}=1.4, \mathrm{CI}=0.80-2.3)$, rural residents $(\mathrm{OR}=1.2, \mathrm{CI}=0.47-2.9)$, and those who completed compulsory education $(\mathrm{OR}=1.8, \mathrm{CI}=0.63-5.2)$, yet the results were not statistically significant. It also reveals that patients who reported having 'sufficient monthly income and save' were significantly at higher risk of current smoking compared with those who had 'insufficient monthly income and loaned' $(\mathrm{OR}=11.2, \mathrm{CI}=2.4-28.9)$. Concerning formal psychiatric diagnoses, patients with single and dual diagnoses of schizophrenia spectrum disorder and bipolar disorder $(\mathrm{OR}=2.0, \mathrm{CI}=1.0-4.3 ; \mathrm{OR}=3.9, \quad \mathrm{CI}=1.2-21.2$; and $\mathrm{OR}=3.1, \mathrm{CI}=1.2-8.0$, respectively) were significantly more likely to be at risk of current smoking compared with those with a depressive disorder. In addition, patients with positive history of hospitalization were significantly at higher risk of smoking compared with their counterparts $(\mathrm{OR}=2.2, \mathrm{CI}=1.3-3.6)$. Although long duration of mental illness (10-20 years) appeared to carry higher risk, it was not statistically significant $(\mathrm{OR}=1.3, \mathrm{CI}=0.75-2.1)$.

Table 2: Distribution of the sampled mentally ill patients according to their smoking status, socio-demographic characteristics and clinical profile

\begin{tabular}{|c|c|c|c|}
\hline \multirow[b]{2}{*}{ Demographic data } & \multicolumn{3}{|c|}{ Smoking status [n \%] } \\
\hline & $\begin{array}{c}\text { Never/ex-smoker } \\
(\mathrm{n}=94) \\
\text { No. }(\%)\end{array}$ & $\begin{array}{l}\text { Current smokers } \\
\qquad(\mathrm{n}=206) \\
\text { No. }(\%)\end{array}$ & OR $(95 \% \mathrm{CI})$ \\
\hline \multicolumn{4}{|l|}{ Age (years) } \\
\hline $18-<30$ & $21(36.8)$ & $36(63.2)$ & 1 \\
\hline $30-<40$ & $40(30.8)$ & $90(69.2)$ & $1.3(0.68-2.5)$ \\
\hline $40-<50$ & $20(31.7)$ & $43(68.3)$ & $1.2(0.58-2.7)$ \\
\hline $50-60$ & $13(26.0)$ & $37(74.0)$ & $1.7(0.72-3.8)$ \\
\hline Mean \pm SD & $36.9 \pm 9.6$ & $38.4 \pm 9.5$ & $\mathrm{t}=0.36(0.857)$ \\
\hline \multicolumn{4}{|l|}{ Marital status } \\
\hline Married & $32(27.1)$ & $86(72.9)$ & $1.4(0.80-2.3)$ \\
\hline Divorced & $6(40.0)$ & $9(60.0)$ & $0.75(0.26-2.2)$ \\
\hline Widowed & $1(33.3)$ & $2(66.7)$ & $1.0(0.09-11.3)$ \\
\hline Single & $55(33.5)$ & $109(66.5)$ & 1 \\
\hline \multicolumn{4}{|l|}{ Education } \\
\hline Illiterate/read and write & $38(34.5)$ & $72(65.5)$ & $0.8(0.32-1.9)$ \\
\hline Compulsory & $11(19.0)$ & $47(81.0)$ & $1.8(0.63-5.2)$ \\
\hline Secondary & $37(35.2)$ & $68(64.8)$ & $0.77(0.31-1.9)$ \\
\hline University & $8(29.6)$ & $19(70.4)$ & 1 \\
\hline \multicolumn{4}{|l|}{ Residence } \\
\hline Rural & $7(28.0)$ & $18(72.0)$ & $1.2(0.47-2.9)$ \\
\hline
\end{tabular}




\begin{tabular}{|c|c|c|c|}
\hline Urban & $87(31.6)$ & $188(68.4)$ & 1 \\
\hline \multicolumn{4}{|l|}{ Monthly income } \\
\hline Sufficient and save & $7(25.9)$ & $20(74.1)$ & $11.2(2.4-28.9)^{*}$ \\
\hline Just sufficient & $57(31.3)$ & $125(68.7)$ & $8.8(1.1-16.7)^{*}$ \\
\hline Insufficient & $26(30.2)$ & $60(69.8)$ & $9.2(1.0-14.7)^{*}$ \\
\hline Insufficient and loan & $4(80.0)$ & $1(20.0)$ & 1 \\
\hline \multicolumn{4}{|l|}{ Clinical profile } \\
\hline \multicolumn{4}{|l|}{ Diagnosis } \\
\hline Depressive disorders & $15(46.9)$ & $17(53.1)$ & 1 \\
\hline Anxiety disorders/OCD & $10(37.0)$ & $17(63.0)$ & $1.5(0.53-4.3)$ \\
\hline Schizophrenia spectrum disorder & $53(30.6)$ & $120(69.4)$ & $2.0(1.0-4.3)^{*}$ \\
\hline Bipolar disorder & $11(22.4)$ & $38(77.6)$ & $3.1(1.2-8.0)^{*}$ \\
\hline Depressive disorder and anxiety disorders & $1(25.0)$ & $3(75.0)$ & $2.6(0.24-28.2)$ \\
\hline Schizophrenia spectrum disorder and depressive disorders & $2(50.0)$ & $2(50.0)$ & $0.88(0.11-7.1)$ \\
\hline Schizophrenia spectrum disorder and bipolar disorder & $2(18.2)$ & $9(81.8)$ & $3.9(1.2-21.2)^{*}$ \\
\hline \multicolumn{4}{|l|}{ Duration of illness (years) } \\
\hline$<10$ & $47(33.1)$ & $95(66.9)$ & 1 \\
\hline $10-$ & $35(28.0)$ & $90(72.0)$ & $1.3(0.75-2.1)$ \\
\hline $20+$ & $12(36.4)$ & $21(63.6)$ & $0.86(0.39-1.9)$ \\
\hline \multicolumn{4}{|l|}{ History of hospitalization } \\
\hline Yes & $49(25.3)$ & $145(74.7)$ & $2.2(1.3-3.6)^{*}$ \\
\hline No & $45(42.5)$ & $61(57.5)$ & 1 \\
\hline
\end{tabular}

CI: confidence interval, OR: odds ratio, *: Statistically significant

\section{DISCUSSION}

In spite of worldwide geographical discrepancies in prevalence rates of smoking in the general population, it has been indicated that smoking rates in people with serious mental illness are disproportionately high compared with the general population ${ }^{[2-4]}$.

In support, the present work indicated a strikingly high prevalence of current smoking (68.7\%) among the sampled mentally ill male patients attending the outpatient clinic of El-Mamoura Psychiatric Hospital in Alexandria. A comparable national estimate reported by WHO (2015) was $47.5 \%$ among adult Egyptian males aged 15 years and over, suggesting that smoking among sampled mentally ill patients was $\sim 1.5$ times that of the general population ${ }^{[1]}$. Age of smoking initiation among mentally ill patients has been debated. Although some studies indicated that mentally ill patients begin smoking at an earlier age than do those without severe mental ill health ${ }^{[17]}$, others reported that most of the mentally ill smokers likely started smoking during youth ${ }^{[4,18]}$. The report of the Surgeon General (2014) indicated that most patients' first use of cigarettes occurred before 18 years of age $(87 \%)^{[3]}$. In support, the present work revealed that the majority of the sampled current smokers started smoking before 18 years of age $(64.5 \%)$. Here, it must be addressed that early use of tobacco has substantial health consequences ${ }^{[19]}$; furthermore, smoking could act as a trigger for mental ill health ${ }^{[18]}$.

Boden et al. ${ }^{[20]}$ indicated that there is a cause-effect relationship between smoking and depression. Despite difficulty in establishing such relationship in the current study owing to utilization of a cross-sectional design, the early age at initiation suggests that smoking probably antedates onset of some mental disorders that commonly start beyond those years.

Several studies have emphasized that people with mental illness are not only more likely to smoke but are also likely to smoke more cigarettes daily compared with the general population ${ }^{[21]}$. Jochelson and Majrowski ${ }^{[22]}$ indicated that in mental health units, $70 \%$ of patients were smokers and $50 \%$ of the smokers were heavy smokers. In agreement, findings of the current work indicated higher rates of heavy smokers compared with the general population, as $42.7 \%$ of the sampled mentally ill current smokers smoked 20-30 cigarettes/day or more, whereas only $4.8 \%$ of adult Egyptian current smokers did ${ }^{[23]}$. Given this high intensity of smoking among mentally ill patients, one might expect high rates of tobacco-related morbidities and mortalities, as well as considerable economic costs.

A research study documents higher prevalence of 
nicotine dependence among individuals with psychiatric disorders compared with the general population ${ }^{[7]}$. The Royal College of Physicians (2013) reported that people with mental health conditions smoked significantly more, had increased levels of nicotine dependence and were therefore at even greater risk of smoking-related harm ${ }^{[5]}$. In support, the current study indicated that nearly threequarters of the current smokers $(75.7 \%)$ were moderately to very highly nicotine dependent. This high prevalence of nicotine dependence in the Arab culture does not only reflect high intensity of cigarette smoking but also other forms of tobacco, most commonly water pipes (shisha).

Hamadeh et al..$^{[24]}$ found that shisha smoking among mentally ill patients was 1.5 times that of the general population, $11.3 \%$ of mentally ill compared with $8.4 \%$ in the general population. In line with these findings, the present work revealed that $25.2 \%$ of the sampled current cigarette smokers (i.e. $17.3 \%$ of the total study sample) were also current shisha smokers. This figure is nearly threefold the national estimates, where $6.2 \%$ of the Egyptian adult males were current shisha smokers ${ }^{[23]}$.

Identifying the stage of readiness to quitting of smokers is the cornerstone of provision of motivational interviewing treatment to smokers. Perhaps understanding motivators to smoking and to quitting is one of the most important issues to address ${ }^{[25]}$. In the current study, several motivators of smoking were reported by the sampled current smokers, the most common of which being a habit $(40.8 \%)$, sense of loneliness $(31.1 \%)$, overcoming anxiety $(28.6 \%)$, and life stresses $(28.2 \%)$. In partial agreement, Clancy et al. ${ }^{[26]}$ mentioned that mood disturbances, sense of hopelessness, lack of control over one's life and a lack of meaningful activities all emerged as important factors contributing to smoking among depressed patients.

Although smokers frequently report using cigarettes to improve their mood, stress, and anxiety, what they often fail to recognize is that they may be using tobacco to prevent and treat unpleasant symptoms of withdrawal ${ }^{[7]}$. It has been documented that both psychiatric inpatients and outpatients, with a variety of diagnoses, are as ready to quit smoking as is the general population ${ }^{[27]}$. An Australian survey (2010) indicated that most current smokers (72\%) reported that they had attempted to quit smoking, of those who had tried to quit smoking, the average number of attempts was $4.5^{[28]}$. In support, the current work indicated that three-quarters of current smokers tried to quit smoking $(75.7 \%)$, where nearly half of them tried to quit $1-2$ times $(50.5 \%)$, whereas $21.3 \%$ tried to quit $3-5$ times. Interestingly, WHO 2015 reported that $42.8 \%$ of current smokers in the Egyptian population expressed willingness to quit ${ }^{[22]}$.

Perhaps, this finding defies false assumptions concerning unwillingness of mentally ill patients to quit smoking. Despite evidence that mentally ill patients who smoke have the same intention to quit as the general population, yet they often lack access to treatment, and even when they do gain access, healthcare providers do not always prioritize smoking cessation for this population and they are not offered the same cessation opportunities as the general population ${ }^{[27]}$. Therefore, it is vital that smokers from this population receive effective smoking cessation interventions.

In line with previous studies, the current study indicated that most current smokers did not receive any physician or psychiatric cessation counseling or treatment interventions by physicians or psychiatrists, where only $41.3 \%$ of current smokers were advised to quit by their psychiatrists, and $61.5 \%$ of those having chronic physical illness received the advice from their physicians. Moreover, most current smokers expressed their need for availability of smoking cessation services $(35.9 \%)$ and of cheap smoking cessation drugs $(42.2 \%)$ to quit.

Thorndike et al. ${ }^{[29]}$ found that psychiatric patients received cessation counseling in only $38 \%$ of their visits to primary care physicians and $12 \%$ of their visits to psychiatrists, whereas Prochaska et al. ${ }^{[30]}$ stated that among 250 psychiatric inpatients, only $1 \%$ were assessed for smoking status, none were assessed for nicotine dependence, and smoking status was never included in treatment plans. Perhaps one of the contributing factors to this treatment gap is the attitudes of mental health staff, as many mental health professionals appear reluctant to engage with patients about smoking and/or have low expectations of patients' motivation or ability to stop smoking.

Successful smoking cessation is often preceded by multiple quitting attempts and motivation to quit. Interestingly, motivators to previous quitting trails reported by current smokers were financial problems (30.3\%), followed by belief in its bad effect $(27.7 \%)$ and having health problems $(25.8 \%)$. These findings underscore the role of health professionals in motivating smokers to change their risky behavior through personalizing the message regarding negative health outcomes of smoking. In line with our finding, Tulloch et al. ${ }^{[31]}$ indicated that health problems was the most common motivator for the upcoming quitting attempt (91.7\%), followed by cost $(31.0 \%)$ and family/social pressures $(28.9 \%)$.

The relatively high prevalence of smoking behavior and nicotine dependence among persons with mental illnesses reflects biological, psychosocial, and cultural factors ${ }^{[21]}$. The sociological perspective draws a strong association between low socioeconomic status and mental illness, with socioeconomic status being a risk factor for the uptake and continued use of tobacco ${ }^{[5]}$. Studies reporting both the prevalence of smoking and demographic and clinical characteristics of smokers with mental illness are scarce ${ }^{[32]}$. However, the few available studies revealed considerable 
controversy concerning sociodemographic determinants among this group. Johnson et al. ${ }^{[33]}$ found that male current smokers with serious mental illness were more likely to have an education level below year 12, to be separated or divorced and to be old (age: 50-59 years).

The present work revealed that current smoking was more likely to be encountered among the older age group (50-60 years old), married patients, those who completed their compulsory education, rural residents, and those with sufficient income. However, risk increased significantly up to 11 times only with higher income strata.

In contradiction to our finding, Centers for Disease Control and Prevention, 2014, indicated that $48 \%$ of people with mental illness who lived below the poverty level smoked, compared with $33 \%$ of those with mental illness who lived above the poverty level ${ }^{[4]}$. This contradiction may be attributed to the fact that people with mental illness particularly those below the poverty level receive financial support provided by social support networks in developed countries.

Results of the present work indicated that a schizophrenic spectrum disorder doubled the risk of current smoking, a bipolar disorder tripled the risk, whereas comorbidity of both disorders raised the risk significantly to fourfold. In support, a meta-analysis of 42 studies from 20 countries reported a $62 \%$ pooled rate of smoking in patients with schizophrenia, which was significantly elevated relative to general population and psychiatric comparison groups $^{[34]}$.

Furthermore, the present study revealed that patients with positive history of hospitalization were significantly at higher risk of being current smokers $(\mathrm{OR}=2.2)$. In support, research data indicated significant association of current smoking and cigarettes consumption with longer illness duration, higher severity of depressive and anxiety symptoms and chronic disease course ${ }^{[35]}$. Moreover, Cooper et $a l .{ }^{[28]}$ indicated that mentally ill patients were significantly more likely to have experienced moderate psychosocial disability, have reported a chronic course of illness and have been hospitalized for their mental illness. This high prevalence of smoking among those with positive history of hospitalization was suggested to reflect the culture of mental healthcare that reinforces tobacco use in treatment settings, residential facilities and housing. It also reflects chronicity and severity of illness of hospitalized patients where the majority of the sample $(60.7 \%)$ had a positive history of hospitalization ${ }^{[28]}$.

Given the high prevalence of smoking and tobaccorelated health consequences among people with mental illness raises, there is a need for developing strategies that address tobacco use in this population not only to improve the long-term health of those with mental disorders but also to provide effective cessation methods that may be applicable to other populations and further our understanding of the mechanisms contributing to both tobacco dependence and psychiatric disorders.

Given the lack of research data concerning smoking behavior among mentally ill people in Egypt, the current study provides valuable information about this risky behavior among an adequate sample of mentally ill male patients attending one of the largest governmental psychiatric hospitals that serves three Egyptian governorates. Despite this, the study had some limitations. The study utilized a cross-sectional design that did not allow investigating the cause-effect relationship between smoking and mental illness. Although the researcher relied on a reliable and brief nicotine dependence self-report assessment tool, the accuracy of the reported information remains questionable. Finally, the study target population was exclusively of male patients (who are 10 times more likely to be smokers), so it could not give us vision on smoking behavior of female patients.

\section{CONCLUSION}

The present work revealed a considerably high prevalence rate of current smoking among the mentally ill patients $(68.7 \%)$. Smoking pattern among this vulnerable group was characterized by early age of initiation $(<18$ years), heavy cigarette smoking, high rate of shisha smoking and high level of nicotine dependence. Current smoking status was significantly associated with high income, single and dual diagnosis of schizophrenia spectrum disorder and/ or bipolar disorder and history of hospitalization. Despite lack of smoking cessation counseling services, evidence for willingness to quit existed among most current smokers. Given the double burden of smoking and mental illness, it is recommended that all professionals working with people with mental disorders should be trained to screen routinely for smoking, to deliver cessation advice and counseling and to provide positive nonsmoking role models. Evidencebased guidelines for management of co-morbid nicotine dependence and mental health problems should be guided by research and be available to providers of mental health services. Considering the fact that early age of smoking initiation is getting higher among age groups of youth, preventive interventions should be initiated during school years.

\section{CONFLICT OF INTEREST}

There are no conflicts of interest.

\section{REFERENCES}

1. World Health Organization (WHO). Report on the global tobacco epidemic, 2015. Country profile Egypt. Geneva: WHO; 2015. 14.

2. World Health Organization (WHO). Global report 
on trends in prevalence of tobacco smoking 2015. Geneva: WHO; 2015.

3. United States Department of Health and Human Services. The health consequences of smoking 50 years of progress. A report of the surgeon general. Atlanta: US Department of Health and Human Services, Centers for Disease Control and Prevention, National Center for Chronic Disease Prevention and Health Promotion; 2014. p. 6.

4. Centers for Disease Control and Prevention (CDC). Vital signs: current cigarette smoking among adults aged $\geq 18$ years with mental illness-United States, 2009-2011. Morb Mortal Wkly Rep 2013; 62:81-87.

5. The Royal College of Physicians. Smoking and mental health. London, UK: RCP; 2013.

6. Lasser K, Boyd JW, Woolhandler S, Himmelstein DU, McCormick D, Bor DH. Smoking and mental illness: a population-based prevalence study. JAMA 2000; 284:2606-2610

7. Chandra PS, Carey MP, Carey KB, Jairam KR, Girish NS, Rudresh HP. Prevalence and correlates of tobacco use and nicotine dependence among psychiatric patients in India. Addict Behav 2005; 30:1290-1299.

8. Al-Haddad NS, Al-Habeeb TA, Abdelgadir MH, AlGhamdy YS, Qureshi NA. Smoking patterns among primary health care attendees, Al-Qassim region, Saudi Arabia. East Mediterr Health J 2003; 9:911-922.

9. Fawzi MH, Fawzi MM, Khedr HH, Fawzi MM. Tobacco smoking in Egyptian schizophrenia patients with and without obsessive-compulsive symptoms. Schizophr Res 2007; 95:236-246.

10. West R, Jarvis, M. Tobacco smoking and mental disorder. Italian J Psychiatr Behav Sci 2005; 15:10-17.

11. Cuijpers P, Smit F, ten Have M, de Graaf R. Smoking is associated with first-ever incidence of mental disorders: a prospective population-based study. Addiction 2007; 102:1303-1309.

12. Levin ED, Rezvani AH. Nicotinic treatment for cognitive dysfunction. Curr Drug Targets CNS Neurol Disord 2002; 1:423-431.

13. Kelly C, McCreadie RG. Smoking habits, current symptoms, and premorbid characteristics of schizophrenic patients in Nithsdale, Scotland. Am J Psychiatry 1999; 156:1751-1757.

14. Hartz SM, Pato CN, Medeiros H, Cavazos-Rehg P,
Sobell JL, Knowle JA et al. Comorbidity of severe psychotic disorders with measures of substance use. JAMA Psychiatry 2014; 71:248-254.

15. Heatherton T, Kozlowski L, Richard C, Frecker, Fagerstrom K. The Fagerstrom test for nicotine dependence: a revision of the fagerstrom tolerance questionnaire. Br J Addict 1991; 86:1119-1127.

16. Fagerström KO, Heatherton F, Kozlowski LT. Nicotine addiction and its assessment. Ear Nose Throat J 1990; 69:763-765.

17. Tsoi DT, Porwal M, Webster AC. Interventions for smoking cessation and reduction in individuals with schizophrenia. Cochrane Database Syst Rev 2013; 2:2.

18. Kelly C, McCreadie RG. Smoking habits, current symptoms, and premorbid characteristics of schizophrenic patients in Nithsdale, Scotland. Am J Psychiatry 1999; 156:1751-1757.

19. United States Department of Health and Human Services. Preventing tobacco use among youth and young adults: a report of the surgeon general. Atlanta: US Department of Health and Human Services, Centers for Disease Control and Prevention, National Center for Chronic Disease Prevention and Health Promotion; 2010. p. 20.

20. Boden JM, Fergusson DM, Horwood LJ. Cigarette smoking and depression: tests of causal linkages using a longitudinal birth cohort. Brit J Psychiat 2010; 196:440-446.

21. D’Mello DA, Bandlamudi GR, Colenda CC. Nicotine replacement methods on a psychiatric unit. Am J Drug Alcohol Ab 2001; 27:525-529.

22. Jochelson J, Majrowski B. Clearing the Air. Debating smoke-free policies in psychiatric units. London: King's Fund; 2006.

23. World Health Organization (WHO). Global adult tobacco survey (GATS). Egypt Country report 2009. Geneva: WHO; 2015.

24. Hamadeh RR, Al Ansari A, Jahrami H, Al Offi A. Cigarette and water pipe smoking among adult patients with severe and persistent mental illness in Bahrain: a comparison with the national non-communicable diseases risk factors survey. BMC Res Notes 2016; 9:77-85.

25. Russo AC, Azevedo RC. Factors that motivate smokers to seek outpatient smoking cessation treatment at a university general hospital. J Bras Pneumol 2010; 36:603-611. 
26. Clancy N, Zwar N, Richmond R. Depression, smoking and smoking cessation: a qualitative study. Fam Pract $2013 ; 30: 587-592$.

27. Siru R, Hulse GK, Tait RJ. Assessing motivation to quit smoking in people with mental illness: a review. Addiction 2009; 104:719-733.

28. Cooper J, Mancuso SG, Borland R, Slade T, Galletly $\mathrm{C}$, Castle D. Tobacco smoking among people living with a psychotic illness: The second Australian survey of psychosis. Aust N Z J Psychiatry 2012; 46:851-863.

29. Thorndike AN, Stafford RS, Rigotti NA. US physicians' treatment of smoking in outpatients with psychiatric diagnoses. Nicotine Tob Res 2001; 3:8591.

30. Prochaska JJ, Gill P, Hall SM. Impact of nicotine withdrawal on an adult inpatient psychiatry unit. Psychiatr Serv 2004; 55:1265-1270.

31. Tulloch HE, Pipe AL, Clyde MJ, Reid RD, Els C. The quit experience and concerns of smokers with psychiatric illness. Am J Prev Med 2016; 50:709-718.

32. Metse AP, Wiggers J, Wye P, Moore L, Clancy R, Wolfenden $\mathrm{L}$ et al. Smoking and environmental characteristics of smokers with a mental illness, and associations with quitting behavior and motivation; a cross sectional study. BMC Public Health $2016 ; 16: 332$.

33. Johnson JL, Ratner PA, Malchy LA, Okoli CT, Procyshyn RM, Bottorff JL et al. Gender-specific profiles of tobacco use among non-institutionalized people with serious mental illness. BMC Psychiatry 2010; 10:101.

34. De Leon J, Diaz FJ. A meta-analysis of worldwide studies demonstrates an association between schizophrenia and tobacco smoking behaviors Schizophr Res 2005; 76:135-157.

35. Jamala $\mathrm{M}$, Willem AJ, Doesa VD, Cuijpersc $\mathrm{P}$, Brenda WJH, Penninxb BW. Association of smoking and nicotine dependence with severity and course of symptoms in patients with depressive or anxiety disorder. Drug Alcohol Depend 2012; 126:138-146. 